\title{
Photochromic 1-benzofurylfulgides with modulated fluorescence
}

\author{
Nadezhda I. Makarova, ${ }^{a}$ Anatoly V. Chernyshev, ${ }^{a}$ Vladimir P. Rybalkin,

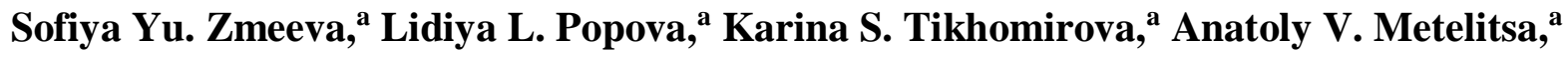 \\ Alexander D. Dubonosov, ${ }^{* b}$ Vladimir A. Bren, ${ }^{a}$ and Vladimir I. Minkin ${ }^{\mathrm{a}, \mathrm{b}}$ \\ ${ }^{a}$ Institute of Physical and Organic Chemistry, Southern Federal University, 194/2, Stachka Av., \\ 344090 Rostov on Don, Russian Federation \\ ${ }^{b}$ Southern Scientific Center of Russian Academy of Sciences,41,Chekhov Pr., \\ 344006 Rostov on Don, Russian Federation \\ E-mail: aled@ipoc.sfedu.ru
}

DOI: https://doi.org/10.24820/ark.5550190.p009.806

\begin{abstract}
Spectral luminescent and photochromic properties of 5-alkoxy-2-methyl-1-benzofuran-3-yl fulgides with increasing alkyl chain length were investigated. All compounds exist in the form of ring-opened $Z$-isomers $\left(\lambda_{\max } 344-346 \mathrm{~nm}\right.$ ). Under UV-irradiation they rearrange into thermally stable colored ring-closed isomers $\left(\lambda_{\max } \sim 500 \mathrm{~nm}\right)$ exhibiting fluorescence emission $\left(\lambda_{\max } 603\right.$ $608 \mathrm{~nm}$ ). Fluorescence in ring-closed form $C$ is modulated by light, irradiation with visible light $(546 \mathrm{~nm})$ results in formation of the initial opened form $O$ and complete quenching of the emission. The quantum efficiency of photodecoloration is by 3.47-4.25 times higher than that of the photocoloration. 5-Alkoxy-2-methyl-1-benzofuran-3-yl fulgides demonstrate high fatigue resistance and are characterized by excellent thermal stability of the photoinduced cyclic form.
\end{abstract}

Keywords: Fulgides, 1-benzofuran, photochromism, fluorescence

\section{Introduction}

Photochromic compounds have already found an important place in the design of novel polyfunctional materials for molecular electronics, molecular logic devices, molecular switches and motors, rewritable optical memory, photodynamic chemo- and biosensors. ${ }^{1-7}$ The lightinduced rearrangement between two metastable isomeric forms of photochromic compounds results in significant changes in various physical properties of the system, such as electronic absorption spectra, fluorescence, dipole moment and nonlinear optic parameters. The most thoroughly studied classes of organic photochromic compounds are represented by spiropyrans and spirooxazines, ${ }^{8,9}$ azobenzenes, ${ }^{10}$ dihetarylethenes, ${ }^{11}$ fulgides and fulgimides. ${ }^{12,13}$ Fulgides, the compounds with the structural skeleton of bismethylenesuccinic anhydride and an aromatic 
or heterocyclic substituent linked to a methylene group, are susceptible to the light-induced hexatriene-cyclohexadiene rearrangement of their ground state colourless ring-opened forms to give coloured ring-closed isomers possessing high fatigue resistance, thermal and photostability capable to display fluorescent, chemosensor and complexing properties. ${ }^{14-16}$ These isomeric forms do not interconvert in dark and have markedly different physical chemical characteristics, which makes fulgides to be promising candidates for the use in high capacity three-dimensional multilayer optical memory devices. ${ }^{17-21}$ The most studied groups of the heterocyclic fulgides are currently represented by furyl-, thienyl-, oxazolyl-, pyrryl-, and indolylfulgides; reports on the synthesis and properties of fulgides with benzofuryl and naphthofuryl groups are relatively scarce. $^{22-24}$

Therefore, the main goal of this work was the investigation into the spectral luminescent and photochromic properties (kinetics of photodecoloration and photocoloration processes, quantum efficiency of photorearrangements, quantum yields of fluorescence) of 5-alkoxy-2-methyl-1benzofuran-3-yl fulgides 1 bearing long alkyl groups allowing application of these photochromic compounds in Langmuir-Blodgett films, which are widely used in the developing of multifunctional materials possessing advanced properties. ${ }^{25}$ A preliminary information on the synthesis of compounds 1 was reported earlier. ${ }^{26}$

\section{Results and Discussion}

According to ${ }^{1} \mathrm{H}$ NMR data ${ }^{26}$ fulgides 1a-c have the structure of ring-opened $Z$-isomers, whereas previously synthesized 5-methoxy-2-methyl-1-benzofuran-3-yl (1a) $)^{23}$ and 5-methoxy-2methylnaphtho[1,2-b]furan-3-yl (2) fulgides ${ }^{22}$ existed in the form of $E$-isomers (Scheme 1).

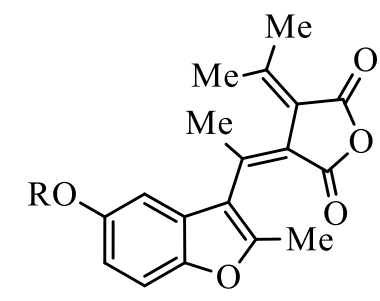

1a-c $Z-O$

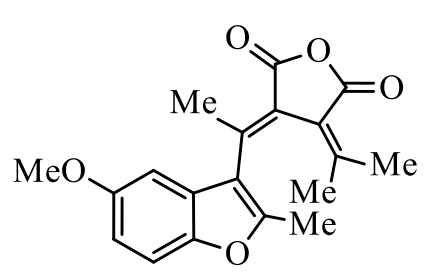

1a $E-O$<smiles>COc1cc2c(C(C)=C3C(=O)OC(=O)C3=C(C)C)c(C)oc2c2ccccc12</smiles>

$2 E-O$

$\mathrm{R}=\mathrm{Me}(\mathbf{a}),\left(\mathrm{CH}_{2}\right)_{5} \mathrm{Me}(\mathbf{b}),\left(\mathrm{CH}_{2}\right)_{15} \mathrm{Me}(\mathbf{c})$

Scheme 1. Structures of 1a-c and 2.

The three-proton singlet signals of isopropylidene methyl groups are found, indeed, in the region of 2.04-2.46 ppm, while for the $E$-structures the characteristic signal appears at 1.12 ppm. ${ }^{23}$ The E-configuration of $\mathbf{2}$ was unequivocally confirmed by the $\mathrm{X}$-ray structural determination. ${ }^{22}$ Spectral and photochromic properties of 1a-c were studied in toluene solutions 
at ambient temperature. Electronic absorption spectra of fulgides 1a-c are characterized by longwave absorption bands with the maxima in the region 344-346 $\mathrm{nm}$ and the molar extinction coefficients $9150-9300 \mathrm{~L} \mathrm{~mol}^{-1} \mathrm{~cm}^{-1}$ (Table 1).

Table 1. Spectral absorption and spectral fluorescent characteristics of isomeric forms of 1a-c and $2^{22}$ in toluene at $T=293 \mathrm{~K}$

\begin{tabular}{|c|c|c|c|c|c|}
\hline \multirow[t]{2}{*}{ Compound } & \multirow{2}{*}{$\begin{array}{l}\text { Isomeric } \\
\text { form }\end{array}$} & \multicolumn{2}{|c|}{ Absorption } & \multirow{2}{*}{$\begin{array}{l}\text { Fluorescence } \\
\text { excitation, } \\
\lambda_{\text {exc }}(\mathrm{nm})\end{array}$} & \multirow{2}{*}{$\begin{array}{l}\text { Fluorescence, } \\
\lambda_{\max }(\mathrm{nm}), \\
\text { (quantum yield) }\end{array}$} \\
\hline & & $\begin{array}{l}\lambda_{\max } \\
(\mathrm{nm})\end{array}$ & $\begin{array}{l}\varepsilon_{\max } \\
\left(\mathrm{L} \mathrm{mol}^{-1} \mathrm{~cm}^{-1}\right)\end{array}$ & & \\
\hline \multirow[t]{2}{*}{$1 \mathbf{a}$} & $Z$ & 344 & 9300 & & \\
\hline & C & 500 & & $\begin{array}{l}370\left(\mathrm{~S}_{0} \rightarrow \mathrm{S}_{2}\right) \\
500\left(\mathrm{~S}_{0} \rightarrow \mathrm{S}_{1}\right)\end{array}$ & $603(0.003)$ \\
\hline \multirow[t]{2}{*}{$1 b$} & $Z$ & 346 & 9200 & & \\
\hline & $C$ & 500 & & $\begin{array}{l}370\left(\mathrm{~S}_{0} \rightarrow \mathrm{S}_{2}\right) \\
500\left(\mathrm{~S}_{0} \rightarrow \mathrm{S}_{1}\right)\end{array}$ & $608(0.004)$ \\
\hline \multirow[t]{2}{*}{ 1c } & $Z$ & 346 & 9150 & & \\
\hline & $C$ & 500 & & $\begin{array}{l}370\left(\mathrm{~S}_{0} \rightarrow \mathrm{S}_{2}\right) \\
500\left(\mathrm{~S}_{0} \rightarrow \mathrm{S}_{1}\right)\end{array}$ & $608(0.005)$ \\
\hline \multirow[t]{2}{*}{2} & $E$ & 344 & 10100 & & \\
\hline & $C$ & 546 & & $\begin{array}{l}340\left(\mathrm{~S}_{0} \rightarrow \mathrm{S}_{2}\right) \\
542\left(\mathrm{~S}_{0} \rightarrow \mathrm{S}_{1}\right)\end{array}$ & $648(0.002)$ \\
\hline
\end{tabular}

The intensity and the position of the absorption maxima of ring-opened $Z$-isomers of the fulgides 1a-c do not practically depend on the length of the alkyl chain. The observed bathochromic shift of a long-wavelength band absorption maximum in the sequence of compounds $\mathrm{R}=\mathrm{Me}(\mathbf{1 a}),\left(\mathrm{CH}_{2}\right)_{5} \mathrm{Me}(\mathbf{1 b})$ and $\left(\mathrm{CH}_{2}\right)_{15} \mathrm{Me}(\mathbf{1 c})$ changes by not more than $2 \mathrm{~nm}$. Ring-opened $Z$-isomers 1a-c do not exhibit fluorescent properties in toluene at ambient temperature. Irradiation of toluene solutions of colorless ring-opened isomers 1a-c with light of $365 \mathrm{~nm}$ wavelength leads to their rose red photocoloration due to the appearance of a new absorption band with a maximum at $500 \mathrm{~nm}$, the intensity of which increases upon irradiation while the intensity of the initial long wavelength absorption band decreases (Fig. 1). These spectral changes are indicative of the occurrence of the electrocyclic rearrangement of hexatriene ring-opened isomer $O$ into 1,3-cyclohexadiene ring-closed form $C$ that involves a prior step of Z/E-isomerization (Table 1, Scheme 2). Ring-closed form $C$ of 5-methoxy-2-methylnaphtho[1,2$b$ ] furan-3-yl fulgide 2 absorbs in a longer wavelength region $\left(\lambda_{\max }=546 \mathrm{~nm}, \Delta \lambda=46 \mathrm{~nm}\right)^{22}$ due to the additional stabilization of aromatic heterocyclic system caused by benzoannelation. 


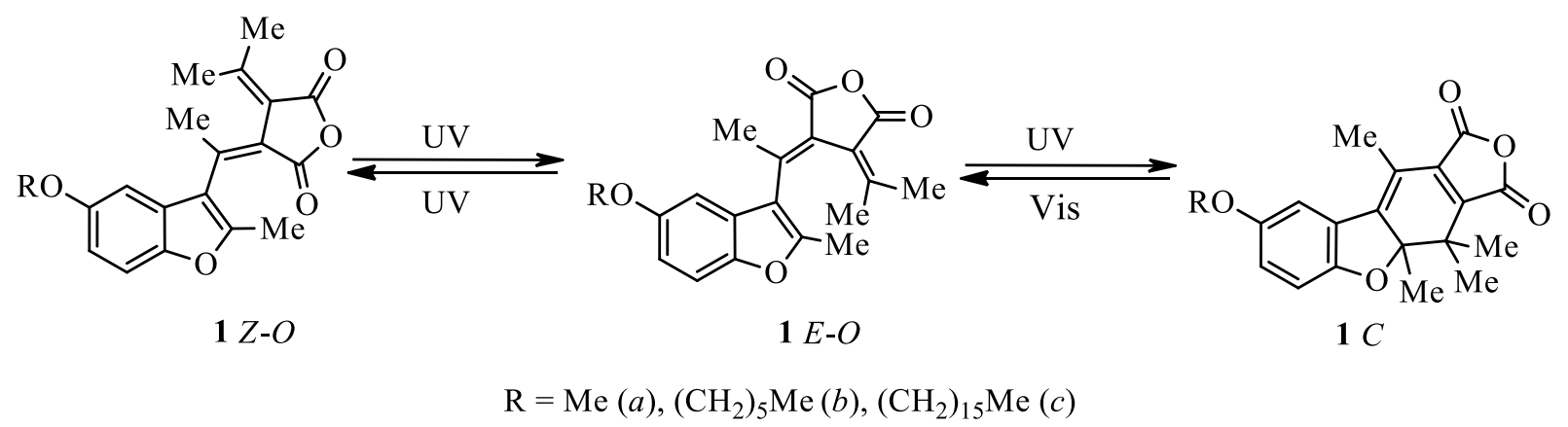

Scheme 2. Photoisomerization of fulgides 1a-c.

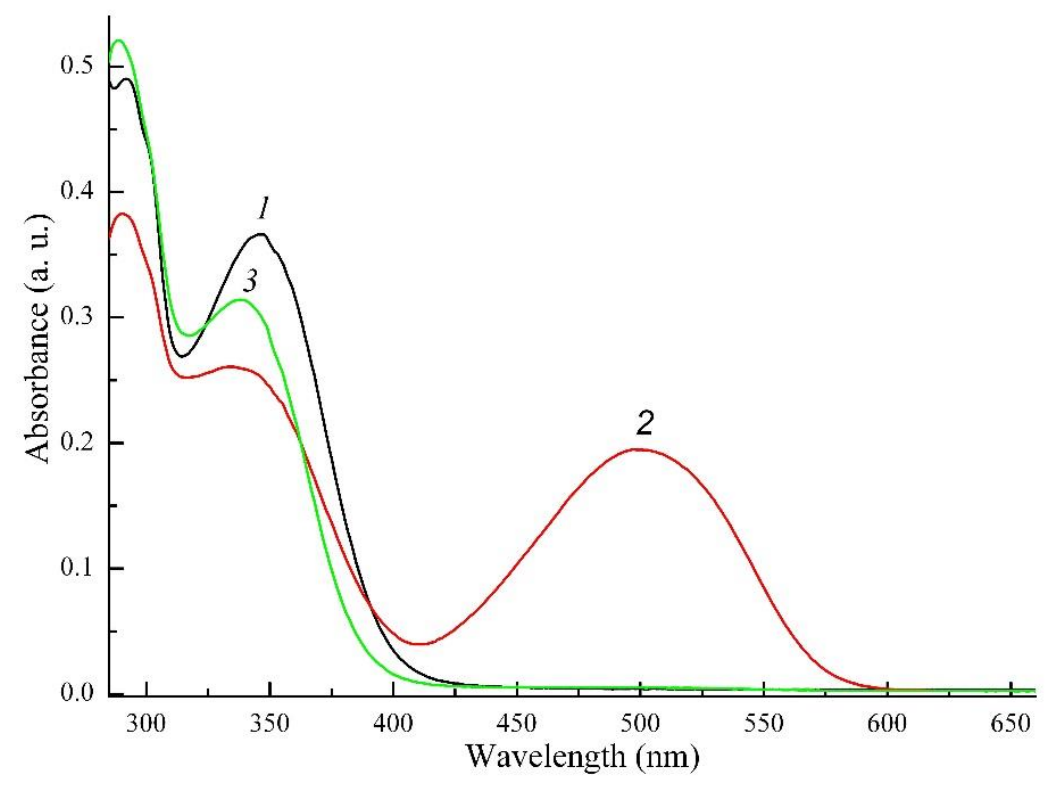

Figure 1. Absorption spectra of fulgide 1c $Z-O$ in toluene $\left(4 \cdot 10^{-5} \mathrm{~mol} \mathrm{~L}^{-1}, T=293 \mathrm{~K}\right)$ corresponding to the initial state (1), to the photostationary state established after irradiation for 12 min with light of $365 \mathrm{~nm}$ wavelength (2) and to the $Z / E-O$ mixture obtained upon subsequent irradiation for $13 \mathrm{~min}$ with light of $546 \mathrm{~nm}$ wavelength (3).

The prolonged UV-irradiation does not lead to the full conversion of 1a-c into colored ringclosed form $C$ due to the establishment of the photostationary state including all isomeric forms, $Z-O, E-O$ and $C$, of the photochromic fulgides (Fig. 1, curve 2). Its formation is caused by the substantial overlap of the absorption bands related to the $\mathrm{S}_{0} \rightarrow \mathrm{S}_{1}$ transition of the initial ringopened form $O$ and the $\mathrm{S}_{0} \rightarrow \mathrm{S}_{2}$ transition of the photoinduced isomer $C$ (Table 1). ${ }^{12-15}$ The subsequent irradiation of colored solutions of 1a-c with visible light $\left(\lambda_{\text {irr }}=546 \mathrm{~nm}\right)$ leads to their photodecoloration due to the reverse ring-opening photoreaction $C \rightarrow E / Z-O$ (Fig.1, curve 3). ${ }^{12,15}$ 
Therefore, no complete restoration of the initial (observed before irradiation) absorption spectra occurs. The recurrence of the initial spectral characteristics can, however, be achieved under a series of repeated cycles of photocoloration-photodecoloration. No spectral changes for the solutions of $C$ forms of 1a-c were found at room temperature after seven days in dark conditions, which indicates the absence of backward thermal processes and high thermal stability of the ring-closed isomers of the studied fulgides.

Ring-closed $C$ forms of fulgides 1a-c exhibit fluorescence of the toluene solutions (Table 1, Fig. 2). Their fluorescence bands maxima are located in the region at 603-608 $\mathrm{nm}$, while the maxima of the fluorescence band of $C$ isomer of 5-methoxy-2-methylnaphtho[1,2- $b$ ]furan-3-yl fulgide 2 was found in the longer wavelength region $\left(\lambda_{\max }=648 \mathrm{~nm}\right){ }^{22}$ Elongation of the alkyl chain in $\mathbf{1 b}$ and $\mathbf{1 c}$ leads to a rather small $(\Delta \lambda=5 \mathrm{~nm})$ bathochromic shift of the fluorescence bands as compared with the methoxy substituted fulgide $\mathbf{1 a}$.

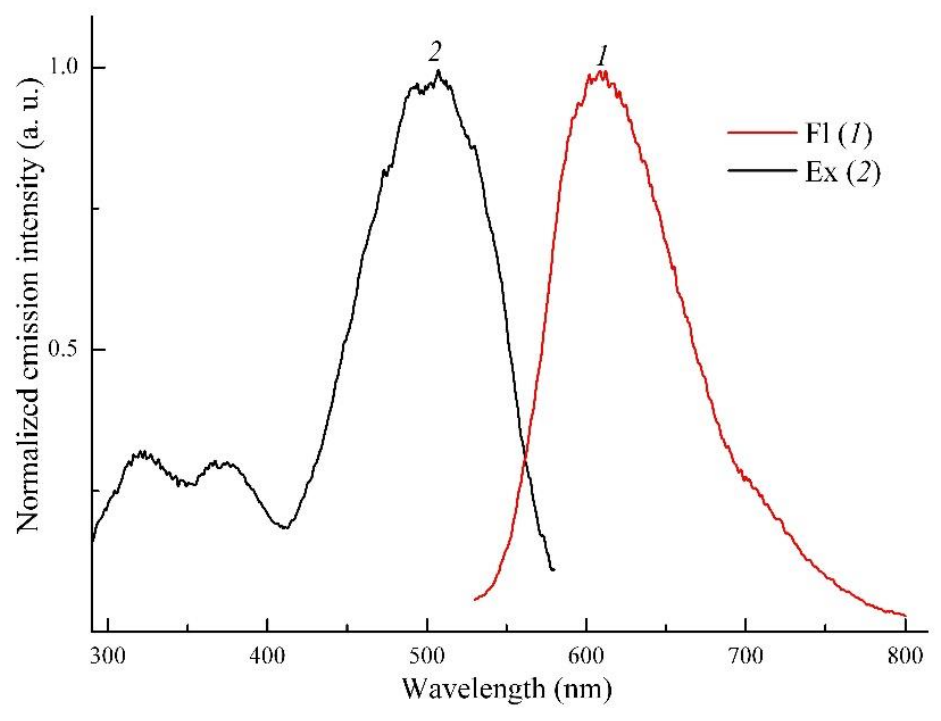

Figure 2. Spectra of fluorescence $(1)\left(\lambda_{\mathrm{exc}}=500 \mathrm{~nm}\right)$ and fluorescence excitation (2) $\left(\lambda_{\mathrm{obs}}=600\right.$ $\mathrm{nm}$ ) of photoisomer $C$ in toluene obtained after irradiation of 1c for 12 min with light of $365 \mathrm{~nm}$ wavelength $\left(4 \cdot 10^{-5} \mathrm{~mol} \mathrm{~L}^{-1}, T=293 \mathrm{~K}\right)$.

Quantum yields of fluorescence of fulgides 1a-c tend to increase with increasing the length of the 5-alkoxy chain: from $0.003(\mathbf{a}, \mathrm{R}=\mathrm{Me})$ to $0.004\left(\mathbf{b}, \mathrm{R}=\left(\mathrm{CH}_{2}\right)_{5} \mathrm{Me}\right)$ and up to $0.005(\mathbf{c}, \mathrm{R}=$ $\left.\left(\mathrm{CH}_{2}\right)_{15} \mathrm{Me}\right)$. For comparison, we determined the quantum yield of fluorescence of $\mathbf{2}$ and found that it is only 0.002 (Table 1). The fluorescence excitation spectra are in good agreement with the long-wavelength absorption of $C$ isomers, which confirms the conclusion that only ring-closed isomers of fulgides 1a-c are responsible for the observed emission properties. In addition, these spectra demonstrate that in the spectral region from 300 to $400 \mathrm{~nm}$ there are two additional bands 
with the maxima at 320 and $370 \mathrm{~nm}$ corresponding to the $S_{0} \rightarrow S_{3}$ and $S_{0} \rightarrow S_{2}$ transitions of the ring-closed isomers of 1a-c (Table 1, Fig. 2). After irradiation of colored solutions of 1a-c with visible light $\left(\lambda_{\text {irr }}=546 \mathrm{~nm}\right)$ the intensity of fluorescence decreases to zero. Consequently, fulgides 1a-c are capable of efficient modulation of the emission by UV/visible light (at least for 10 cycles) while for previously known 1-benzofuryl fulgides little modulation of the fluorescence was achieved ${ }^{23}$ and their resistance to photodegradation was insufficient (two switching cycles).

Fulgides 1a-c manifest high resistance to photodegradation. As shown in Fig. 3 by an example of 1c, the optical density in the maximum of absorption band of $C$ form (in the photostationary state) remained practically unchanged within 10 photocolorationphotodecoloration cycles. Accordingly, no changes in fluorescence intensity of $C$ form (in the photostationary state) were detected.

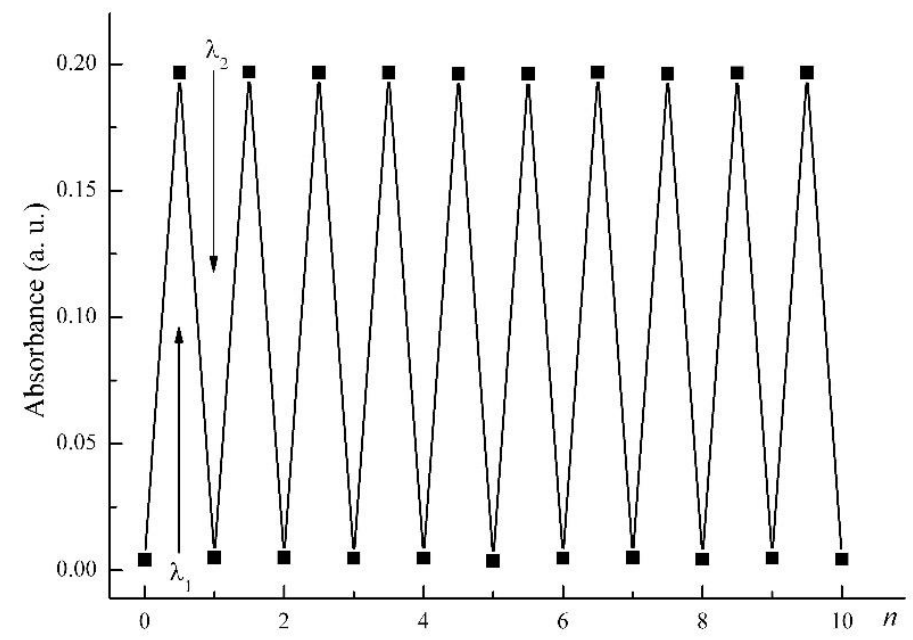

Figure 3. Optical density dynamics of fulgide 1c in toluene at $\lambda_{\text {obs }}=500 \mathrm{~nm}$ (the absorbance band maximum of the ring-closed $C$ isomer) under photocoloration $\left(\lambda_{1}=365 \mathrm{~nm}, \tau=12 \min \right)$ photodecoloration $\left(\lambda_{2}=546 \mathrm{~nm}, \tau=13 \mathrm{~min}\right)$ cycling; $n$ is the number of cycles.

As a convenient integral parameter for the evaluation of efficiency of the photocoloration and photodecoloration processes, we used colorability, which is defined as the product of quantum yield of photocoloration (photodecoloration) and molar absorption coefficient of the photoinduced form: ${ }^{27} \Phi_{Z(E)}{ }^{\circ} \varepsilon_{\max }{ }^{C}$ (for the overall process $Z \rightarrow E \rightarrow C$, including two sequential photoinduced reactions $-Z / E$-photoisomerization and subsequent $E \rightarrow C$ photocyclization) and

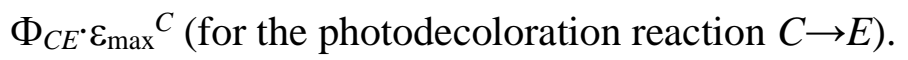


Table 2. The values of colorabilities of fulgides 1a-c in toluene at $T=293 \mathrm{~K}$ : (photocoloration -

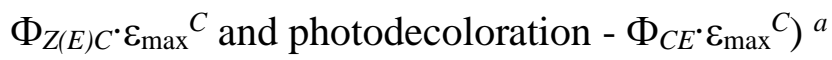

\begin{tabular}{llcl}
\hline Compound & \multicolumn{1}{c}{$\Phi_{Z(E) C^{*} \varepsilon_{\max }{ }^{C}}$} & $\Phi_{C E^{*} \varepsilon_{\max }{ }^{C}} \Phi_{Z(E) C} / \Phi_{C E}$ \\
\cline { 2 - 3 } & & $\mathrm{M}^{-1} \mathrm{~cm}^{-1}$ & 0.29 \\
$\mathbf{1 a}$ & 337 & 1170 & 0.24 \\
$\mathbf{1 b}$ & 273 & 1160 & 0.26 \\
$\mathbf{1 c}$ & 277 & 1074 & \\
\hline
\end{tabular}

${ }^{a} \Phi_{Z(E) C}$ and $\Phi_{C E}$ - quantum yields of photocoloration (cyclization) and photodecoloration (opening of the ring) reactions, correspondingly; $\varepsilon_{\max }{ }^{C}-$ the value of a molar extinction coefficient at the absorption band maximum of the photoinduced ring-closed form $C$.

The determined values of the efficiencies of the photocoloration reactions $Z \rightarrow E \rightarrow C$ of fulgides 1a-c show a slight dependence on the substituents $\left(277-337 \mathrm{M}^{-1} \mathrm{~cm}^{-1}\right)$. The efficiencies of the photodecoloration reactions $C \rightarrow E$ are at 3.47-4.25 times higher than the corresponding parameters of the photocoloration (Table 2). The ratio of the quantum yields of the photocoloration to the quantum yields of the photodecoloration $\left(\Phi_{Z(E) C} / \Phi_{C E}\right)$ obtained for 1a-c on the basis of these data are 0.24-0.29 that indicates significantly higher efficiency of the photoinduced reaction of the cycle opening $(C \rightarrow E)$ (Table 2).

\section{Conclusions}

Thus, 5-alkoxy-2-methyl-1-benzofuran-3-yl fulgides 1b,c, possesing long alkyl substituents, represent novel photochromic compounds with modulated fluorescence. UV-irradiation of their ring-opened isomers $O$ results in the rearrangement into thermally stable pink-colored ringclosed forms $C$ exhibiting fluorescence properties in contrast to the initial $O$ structures. The irradiation of ring-closed isomeric forms with visible light leads to their re-opening and complete fluorescence quenching.

\section{Experimental Section}

General. 3-[1-(5-Methoxy- (1a), 3-[1-(5-hexyloxy- (1b) and 3-[1-(5-hexadecyloxy-2-methyl-1benzofuran-3-yl)ethylidene]-4-(1-methylethylidene)dihydro-2,5-furandione

(1c) were synthesized earlier following the principles of the Stobbe condensation. ${ }^{26}$ Their purity (>98\%) was confirmed by thin layer chromatography and by ${ }^{1} \mathrm{H}$ NMR spectroscopy.

The electronic absorption spectra were recorded on a Varian Cary 100 spectrophotometer, the emission spectra - on a Varian Cary Eclipse spectrofluorimeter. Toluene of the spectroscopic 
grade (Aldrich) was used to prepare solutions. The fluorescence quantum yields were determined by the Parker-Rice method ${ }^{28}$ using methylene blue in water $\left(\varphi=0.02, \lambda_{\text {irr }}=540 \mathrm{~nm}\right)$ as a standard luminophore. ${ }^{29}$ The solutions were irradiated in a quartz cell $(l=1 \mathrm{~cm})$ with a DRSh250 mercury lamp using a set of interferential light filters to allocate mercury spectral lines (365 and $546 \mathrm{~nm}$ ). The kinetic photocoloration curves of fulgide solutions were recorded directly during irradiation on a Cary 50 spectrophotometer equipped with the temperature-controlled cell. A xenon lamp with a monochromator for allocation of narrow spectral lines (Newport) was used as a radiation source. The intensity of light source was determined using a Newport 2935 power meter for optical radiation. The irradiation light intensity at 365 and $546 \mathrm{~nm}$ was determined as $3.83 \cdot 10^{15}$ and $5.68 \cdot 10^{15}$ photon $^{-1} \mathrm{~s}^{-1}$, correspondingly. Colorability parameters $\Phi_{Z(E) C^{*}} \varepsilon_{\max }{ }^{C}$ and

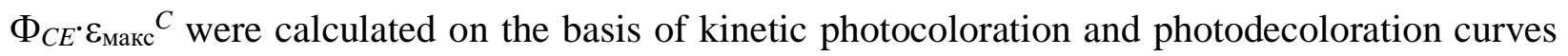
using the procedure. ${ }^{27}$

\section{Acknowledgements}

This research was supported by The Ministry of Education and Science of Russian Federation in the framework of the State Assignment for Research (Project No. 1895).

\section{References}

1. Crano, J. C.; Guglielmetti, R. J. Organic photochromic and thermochromic compounds; Plenum Press: New York, 1999.

2. Andreasson, J.; Pischel, U. Chem. Soc. Rev. 2015, 44, 1053. http://dx.doi.org/10.1039/C4CS00342J

3. Zhang, J.; Zou, Q.; Tian, H. Adv. Mater. 2013, 25, 378. http://dx.doi.org/10.1002/adma.201201521

4. Natali, M.; Giordani, S. Chem. Soc. Rev. 2012, 41, 4010. http://dx.doi.org/10.1039/C2CS35015G

5. Wang, G.; Zhang, J. J. Photochem. Photobiol. C: Photochem. Rev. 2012, 13, 299. http://dx.doi.org/10.1016/j.jphotochemrev.2012.06.002.

6. Feringa, B. L. J. Org. Chem. 2007, 72, 6635. http://dx.doi.org/10.1021/jo070394d

7. Cusido, J.; Deniz, E.; Raymo, F. M. Eur. J. Org. Chem. 2009, 13, 2031. http://dx.doi.org/10.1002/ejoc.200801244

8. Minkin, V. I. Chem. Rev._2004, 104, 2751. http://dx.doi.org/10.1021/cr020088u

9. Klajn, R. Chem. Soc. Rev. 2014, 43, 148. http://dx.doi.org/10.1039/C3CS60181A 
10. Zhao, X. Y.; Wang, M. Z. Eur. Polym. J. 2006, 42, 247.

http://dx.doi.org/10.1016/j.eurpolymj.2005.08.007

11. Irie, M. Chem. Rev. 2000, 100, 1685.

http://dx.doi.org/10.1021/cr980069d

12. Yokoyama, Y. Chem. Rev. 2000, 100, 1717.

http://dx.doi.org/10.1021/cr980070c

13. Rueck-Braun, K.; Mayer, K.; Hebert, A.; Michalik, F. in Organic Photochemistry and Photobiology; Griesbeck, A.; Oelgemöller, M.; Ghetti, F. Eds.; CRC Press: Boca Raton, 2012; pp 607-626.

14. Yokoyama, Y.; Gushiken, T.; Ubukata, T. in Molecular Switches; Feringa, B. L.; Browne, W. R. Eds.; Wiley: Weinheim, 2011; pp 81-95.

15. Yokoyama, Y.; Kose, M. (2004). in Organic Photochemistry and Photobiology; Horspool, W., Lenci, F. Eds.; CRC Press: Boca Raton, 2004; Ch. 86, pp 1-13.

16. Rybalkin, V. P.; Pluzhnikova, S. Yu.; Popova, L. L.; Revinskii, Yu. V.; Tikhomirova, K. S.; Komissarova, O.A.; Dubonosov, A. D.; Bren, V. A.; Minkin, V. I. Mendeleev Comm. 2016, 26, 21. http://dx.doi.org/10.1016/j.mencom.2016.01.009

17. Yokoyama, Y.; Kose, M. J. Photochem. Photobiol. A: Chem. 2004, 166, 9. http://dx.doi.org/10.1016/j.jphotochem.2004.04.023

18. Liang, Y. C.; Dvornikov, A. S.; Rentzepis, P.M. Macromolecules 2002, 35, 9377. http://dx.doi.org/10.1021/ma020750o

19. Liang, Y. C.; Dvornikov, A. S.; Rentzepis, P. M. Res. Chem. Intermed. 1998, 24, 905. http://dx.doi.org/10.1163/156856798X00609

20. Yokoyama, Y.; Tanaka, T.; Yamane, T.; Kurita, Y. Chem. Lett. 1991, 20, 1125. http://dx.doi.org/10.1246/cl.1991.1125

21 Liang, Y. C.; Dvornikov, A. S.; Rentzepis, P.M. Optics Comm. 2003, 223, 61. http://dx.doi.org/10.1016/S0030-4018(03)01631-6

22. Balenko, S. K.; Makarova, N. I.; Rybalkin, V. P.; Shepelenko, E. N.; Popova, L. L.; Tkachev, V. V.; Aldoshin, S. M.; Metelitsa, A. V.; Bren, V. A.; Minkin, V. I. Russ. Chem. Bull._2010, $59,954$.

http://dx.doi.org/10.1007/s11172-010-0189-x

23. Strübe, F.; Rath, S.; Mattay, J. Eur. J. Org. Chem. 2011, 4645. http://dx.doi.org/10.1002/ejoc.201100228

24. Strübe, F.; Siewertsen, R.; Sönnichsen, F. D.; Renth, F.; Temps, F.; Mattay, J. Eur. J. Org. Chem. 2011, 1947.

http://dx.doi.org/10.1002/ejoc.201001649

25. Zaitsev, S. Yu.; Solovyeva, D. O.; Zaitsev, I. S. Adv. Colloid Interface Sci. 2015, 222, 755. http://dx.doi.org/10.1016/i.cis.2014.09.007 
26. Rybalkin, V. P.; Makarova, N. I.; Pluzhnikova, S. Yu.; Popova, L. L.; Metelitsa, A. V.; Bren, V. A.; Minkin, V. I. Russ. Chem. Bull. 2014, 63, 1780.

http://dx.doi.org/10.1007/s11172-014-0667-7

27. Appriou, P.; Guglielmetti, R.; Garnier, F. J. Photochem. 1978, 8, 145. http://dx.doi.org/10.1016/0047-2670(78)80016-1

28. Parker, C. A. Photoluminescence of Solutions; Elsevier: Amsterdam-London-New York, 1968.

29. Atherton, S. J.; Harriman, A. J. Am. Chem. Soc. 1993, 115, 1816. http://dx.doi.org/10.1021/ja00058a028 